\title{
Service with a Smile: Roles of Emotional Intelligence and Affectivity on the Use of Emotional Labour Strategies Among Bank Employees
}

\author{
Anthony G. Balogun ${ }^{1, ~ *, ~ S h y n g l e ~ K . ~ B a l o g u n ², ~ B a m i k o l e ~ E . ~ A g e s i n ~}{ }^{1}$ \\ ${ }^{1}$ Department of Pure and Applied Psychology, Adekunle Ajasin University, Akungba-Akoko, Ondo State, Nigeria \\ ${ }^{2}$ Department of Psychology, University of Ibadan, Ibadan, Oyo State, Nigeria
}

Email address:

tonybalogun17@yahoo.com (A. G. Balogun)

\section{To cite this article:}

Anthony G. Balogun, Shyngle K. Balogun, Bamikole E. Agesin. Service with a Smile: Roles of Emotional Intelligence and Affectivity on the Use of Emotional Labour Strategies Among Bank Employees. Psychology and Behavioral Sciences. Vol. 5, No. 1, 2016 , pp. 37-44.

doi: $10.11648 /$ j.pbs. 20160501.15

\begin{abstract}
The purpose of this study was to examine whether emotional intelligence and affectivity will predict the use of emotional labour strategies among bank employees in Nigeria, who are presently facing higher emotional demands. This study was a cross-sectional survey study, in which 277 (males $=126$; females $=151$ ) bank employees were selected from branches of some commercial banks in the capital city of Ondo State, Nigeria, using a convenience sampling technique. Results of the hierarchical multiple regression analysis indicated that bank employees with higher emotional intelligence and positive affectivity tend to utilize deep acting while those with low emotional intelligence and negative affectivity tend to utilize surface acting. These findings have implications for training, recruitment, and selection exercises.
\end{abstract}

Keywords: Affectivity, Emotional Labour, Emotional Intelligence, Bank Employees

\section{Introduction}

Emotional labour, the regulation of emotional feelings and expression at work, is increasingly becoming a focus of research as more workers are holding jobs that require them to frequently regulate their emotions as they interact everyday with customers or clients (Chau, Dahling, Levy, \& Diefendorff, 2009; Dahling \& Perez, 2010; Noor \& Zainuddin, 2011). Emotional labour is particularly important in service industries because of its implications for effective service delivery, customers' satisfaction and patronage, and job performance (Bolton, 2005; Morris \& Feldman, 1996; Wharton \& Erickson, 1993; Zeithaml, Bitner, \& Gremler, 2006).

Banking industry is a service industry characterized by frequent interaction between employees and customers. This interaction is a pivotal aspect of the service it seeks to provide and the experiences that customers remember best. To provide excellent service that will satisfy and keep extant customers and attract new customers, various banks impose display rules that mandate their staff to display positive emotions such as friendliness, cheerfulness, warmth, enthusiasm, or confidence and suppress negative emotions (e.g. fear and anger) while interacting with customers
(Amazue, Onyishi, \& Amazue, 2014; Bolton, 2005; Zeithaml, Bitner, \& Gremler, 2006).

However, in the course of performing their daily onus, bank employees may experience feelings (e.g. sadness or anger) that contradict the positive display rules of bank, thus prompting a discrepancy between felt emotions and required emotions - i.e. emotional dissonance (Hochschild, 1983). But because that is what they are paid to do, bank employees must regulate their felt emotions and emotional display to create a favourable atmosphere in which interpersonal transaction takes place.

Since bank employees will not always be in a good mood, they have to rely on compensatory strategies called emotional labour strategies, to regulate both their feelings and the way they are expressed, in order to meet organizational demands (Diefendroff, Croyle, \& Gosserand, 2005; Grandey, 2000). Hochschild (1983) identified two emotional labour strategies that service employees utilize to bring about the emotional displays that are required by their employers. These are deep acting and surface acting. Employees who exhibit deep acting change or modify felt emotion to suit job-required emotion whereas in surface acting, the employee only alter their display emotions without modifying felt emotions (e.g. 
when an angry bank employee fakes a smile to satisfy the customers service requirement of the job).

Ample studies (e.g., Brotheridge, 2006; Cheung \& Tang, 2009; Dahling \& Perez, 2010; Ehigie, Oguntuase, Ibode, \& Ehigie, 2012) have examined the roles of individual factors (e.g. personality traits and emotional intelligence) on the use of these two emotional labour strategies (i.e. deep acting and surface acting) in recent years. However, most of these studies focused more on service industries such as schools, hospitals, hotels; but not so much has been done on employees in the banking industry. In Nigeria in particular, there is dearth of literature in this perspective.

The purpose of this study is to investigate the extent to which emotional intelligence and affectivity (positive affectivity and negative affectivity) predict the use of emotional labour strategies among bank employees in Nigeria, who are currently facing higher emotional demands (Balogun, 2014). This study would help bank managers to design training strategies that will assist bank employees to perform emotional labour with the emotional labour strategy that will be less stressful for them and that would in turn enhance effective service delivery, increase customers' patronage, and attract more customers in the present competitive market.

\section{Literature Review and Hypotheses}

\subsection{Emotional Labour Strategies: An Overview}

Emotional labour refers to the regulation and expression of organizationally desired emotions at work in order to fulfill the emotional display requirement of the organizations or job (Ashforth \& Humphrey, 1993; Grandey, 2000; Hochschild, 1983). It is an act of altering one's inner or outward emotions in congruence with organisational display rules.

Most previous studies have described two general acting mechanisms that employees utilize to express emotions required by their employers (Ashforth \& Humphrey, 1993; Grandey, 2000; Hochschild, 1983). Because this approach to understanding emotional labour positions the employees as actors responding to organisational demands (Dahling et al. 2010), Hochschild (1983) described it as dramaturgical strategies.

The first dramaturgical strategy, deep acting, involves managing felt emotions. When deep acting, employees change their feelings to elicit an authentic emotional display that is consistent with organisational requirements (Dahling et al. 2010). For example, an unhappy service employee who is expected to interact with customers in a positive manner might choose to deliberately reflect on positive thoughts to elicit a positive mood, which subsequently generate natural display emotions such as happiness and enthusiasm. Deep acting has been described as "acting in good faith" because the display emotion is genuinely connected to the underlying emotional experiences (Grandey, 2000).

In contrast, the second dramaturgical strategy, surface acting, involves managing only the observable emotional expression (Dahling et al. 2010). An employee only changes their display emotions without modifying felt emotions (Dahling et al. 2010; Grandey, 2000). For example, an angry service employee may fake a smile to satisfy the customer service requirements of the job despite his/her unchanged internal feeling of anger (Ogungbamila, Balogun, Ogungbamila, \& Oladele, 2014). Consequently, surface acting has been described as "acting in bad faith" because it entails changing of emotional displays without modifying internal feelings (Grandey, 2003).

Although, both surface acting and deep acting can be effective means of regulating emotions, there are different outcomes associated with these two strategies when they are used habitually (Côté, 2005). Surface acting is associated with more negative outcomes because it generates a sense of emotional dissonance (incongruence between felt and displayed emotions) and requires constant effort to maintain the facade of the appropriate emotional display. For example, research indicates that surface acting is positively related to stress, emotional exhaustion, burnout syndrome, and poor service delivery (Brotheridge \& Lee; Grandey, 2003; Karatepe \& Aleshinloye, 2009). Deep acting on the other hand, is related to more positive outcomes such as affective well-being, personal authenticity, and high sense of professional efficacy (Johnson \& Spector, 2007).

The pattern of findings reported in previous research suggests that service organisations stand to benefit more by encouraging employees to deep act instead of surface act (Bono \& Vey, 2005; Dahling et al. 2010). However, one may argue that as long as customers receive the desired service and perceive employee to be offering the correct emotional response, customers may not care whether the response is genuine or not. The danger here is that the more an employee surface act and constantly invests effort to maintain the facade of the appropriate emotional display, the more he/she is likely to experience stress, emotional dissonance, and emotional exhaustion. An emotionally exhausted employee is likely to be less satisfied and committed to the job, which may consequently result to poor service delivery (Johnson, 2004).

\subsection{Emotional Intelligence and Emotional Labour Strategies}

Emotional intelligence refers to an individual ability to generate, perceive, appraise, and express, understand, and make use of one and others emotions accurately (Goleman, 1998). It is the ability to regulate emotions to promote emotional and intellectual growth and well-being (Salovey \& Mayer, 1990). Emotional intelligence refers to "the ability to recognize and use information in social interactions" (Grandey, 2000, p. 106). Individuals with high emotional intelligence, compared with those with low emotional intelligence, are skilled in handling and regulating their emotions to suit social interactions (Goleman, 1995). Thus, such individuals may be better equipped to engage in emotional labour in order to satisfy display rules and contribute to a positive service experience for the customers (Ehigie et al. 2012; Johnson \& Spector, 2007). 
Past studies have shown that service employees with high emotional intelligence tend to utilize deep acting than surface acting when trying to fake emotions in job that calls for expression of positive emotions (Côté, 2005). For example, Ehigie, et al. (2012) found that frontline hotel workers who are emotionally intelligent tend to utilize deep acting than surface acting. In a correlation analysis, Brotheridge (2006) also reported that tendency to deep act increases as employees' levels of emotional intelligence increases. Moreover, Dore and Austin (2006) found that emotional intelligence is positively correlated with deep acting, suggesting that high emotional intelligence enhances the performance of deep acting. Côté (2005) findings revealed that individuals high in emotional intelligence find it more natural to engage in emotional labour by deep acting.

This may be because highly emotional intelligent employees know when and how to express emotions, as they do with controlling it (Salovey et al. 1990). In addition, employees with higher levels of emotional intelligence are capable of creating positive emotions in themselves. Being able to create positive emotions in oneself is a component of effective deep acting (Chau, Dahling, Levy, \& Diefendorff, 2009), whereby individuals align their internal emotions with the integrative display requirements.

Conversely, service employees with low levels of emotional intelligence may tend to utilize surface acting, which is a relatively simple, response-focused approach to managing emotions. Grandey (2000) submitted that individuals who do not know how to regulate their felt emotions (i.e. low emotional intelligence) tend to engage more in surface acting and less in deep acting especially when the display rules calls for expression of positive emotions. This may be because individuals with low emotional intelligence lack the necessary skills to employ more adaptive emotion regulation strategies such as deep acting. Thus, these individuals may choose to surface act, which is a relatively simple, response-focused approach to managing emotions. Thus, we hypothesize that:

H1: Emotional intelligence will positively relate to deep acting but negatively relate to surface acting.

\subsection{Affectivity and Emotional Labour Strategies}

Affective trait, an individual relatively stable mood state, can influence service employees' use of emotional labour strategies. Grandey (2000) identify two types of affectivity traits; positive affectivity (PA) and negative affectivity (NA). $\mathrm{PA}$ is the relatively stable and dispositional tendency for a person to experience positive emotions. PA corresponds to enthusiastic, optimism, and happiness. NA on the other hand, is the dispositional tendency to experience negative emotions. NA is related to pessimism and aversive mood states (Grandey, 2000).

According to Weiss and Cropanzano (1996), affective traits serve as predispositions to particular emotional responses. Morris and Feldman (1996) contend that an individual's predisposition to experience positive or negative affect will influence emotional dissonance. For example, if the organizationally prescribed emotions conflicted with an employee's affectivity, emotional dissonance may occur. However, individuals whose display rule requirements are congruent with their affective states may experience fewer negative outcomes such as emotional dissonance.

Previous research has shown that individuals with negative affectivity tend to engage in surface acting than deep acting when jobs require positive emotions (Brotheridge \& Grandey, 2002; Brotheridge \& Lee, 2003; Gosserand \& Diefendorff, 2005; Cheung \& Tang 2009). Negative affect service employees may surface act in order to obey these positive display rules because these rules calls for expressions that conflict with their general negative mood states. Since these individuals are always in negative or bad moods, surface acting which only modifies the expression and not the feeling would be chosen more frequently than deep acting which modifies the feelings.

In contrast, service workers with positive affectivity may always utilize deep acting especially when the job calls for the expression of positive emotions. For example, Johnson (2004) found that positive affectivity was positively related to deep acting. Similarly, Gosserand et al. (2005) reported a positive relationship between positive affectivity and deep acting, and a negative but non-significant relationship between negative affectivity and deep acting. Using 486 Chinese employees, Cheung and Tang (2009) found that positive affectivity correlated positively with deep acting. When service industry display rules mandate the expression of positive emotions and suppression of negative emotions, the display rules are more likely to be favourable to service employees with positive affect states, because this approximates their natural state of being i.e. positive mood states. Although, individuals with positive affectivity seldom experience negative emotions that conflict with positive display rules, however, their positive affect state makes it easier for them to change or modify their feelings via deep acting than surface acting.

Therefore, we suggest that negative affect bank employees may tend to embrace surface acting to meet integrative/positive display rules, because such a strategy may only enable them to change their emotional expressions instead of their internal feelings. Conversely, bank employees with positive affect may tend to utilize deep acting to meet positive display rules because modification of their currently positive state to a more disposition-appropriate positive state may reduce emotional dissonance and its attendant negative consequences. Hence, we hypothesize that:

$H 2$ : Positive affectivity will positively relate to deep acting but negatively relate to surface acting.

H3: Negative affectivity will positively relate to surface acting but negatively relate to deep acting.

\section{Method}

Design and Participants.

This study was a cross-sectional survey study, in which 277 bank employees comprising of 126 (45.5\%) males and 
$151(54.5 \%)$ females were selected from branches of some commercial banks in the capital city of Ondo State, Nigeria, using a convenience sampling technique. The ages of the participants ranged between 18 and 56 years with a mean of $32.80(\mathrm{SD}=8.83)$. They also varied in terms of academic qualification, $121(43.7 \%)$ had NCE/OND certificates, 142 $(51.3 \%)$ had first degree, 14 (5.1\%) had postgraduate degree. Regarding their job status, $197(71.12 \%)$ of the participants were in junior cadre while $80(28.88 \%)$ were in senior cadre. Their job tenure ranged between 3 and 12 years.

\section{Measures}

Emotional Intelligence: This was measured using Wong and Law Emotional Intelligence Scale (WLEIS) (Wong \& Law, 2002). The scale comprises of 16-item, organized into four dimensions: Self-Emotional Appraisal (SEA), Others' Emotional Appraisal (OEA), Regulation of Emotion (ROE), and Use of Emotion (UOE). Example items include: "I have good understanding of my own emotions"; "I always know my friends' emotions from their behavior"; and "I am able to control my temper and handle difficulties rationally". The items are rated on a 7-point Likert format ranging from $1=$ strongly disagree to $7=$ strongly agree. In the present study, a Cronbach's alpha of .69 was obtained for the overall scale. Higher score indicate relatively higher levels of emotional intelligence.

Affectivity: This was measured using 20-item Positive Affectivity and Negative Affectivity Scale (PANAS) developed by Watson, Clark and Tellegen (1988). The 20item consisted of ten emotion words for each type of affectivity, for instance, positive affectivity items include interested and excited, while negative affectivity items include distressed and upset. The PANAS measures both positive and negative affectivity using a five-point Likert format that ranges from $1=$ very slightly or not at all to $2=$ extremely. Watson, et al. (1988) reported internal consistency reliabilities for both the positive (.88) and negative affectivity scales (.87). In the present study, we obtained a Cronbach's alpha of .87 and .89 for positive affectivity and negative affectivity respectively. High scores on positive affectivity correspond to high levels of positive traits. High scores on negative affectivity correspond to high levels of negative traits.

Emotional Labour: This was measured using an adapted 19-item Hospitality Emotional Labour Scale developed by Chu (2002). The scale was designed to measure deep acting and surface acting of emotional labour. Items were scored on a 5-point scale (always $=5$; never $=1$ ). Sample item include: "I have to cover my true feelings when dealing with customers". Ogungbamila, Balogun Ogungbamila, and Oladele (2014) obtained a Cronbach's alpha of .71 for the scale. In the present study, a Cronbach's alpha of .77 was obtained. The higher the score of an employee on the surface acting subscale, the more he/she engaged in surface acting. Higher scores in deep acting subscale implies that employee tend to engage in deep acting.

\section{Procedures}

The researchers consulted the managers of the branches of some commercial banks situated in Akure metropolis to obtain permission for the research exercise. The managers of these banks were briefed about the purpose and all gave their approval to conduct the research. Using a convenience sampling technique (because of the busy schedule of bank employees), 300 questionnaires were administered to participants that consented. Prior to the administration of the questionnaires, participants were informed about the aim of the study. The participants were told that participation in the study was voluntary and they could discontinue their participation at any time. They were also given assurance of anonymity and informed that their responses would be kept confidential. Out of the 300 questionnaires administered, 291 were retrieved in which 277 were adequately completed and found usable. This yielded a response rate of $97 \%$.

\section{Results}

Bivariate analysis was performed on the data to test for relationships among the variables of the study. The results are presented in Table 1.

Table 1. Mean, Standard Deviation, and Inter-Variable Correlations.

\begin{tabular}{|c|c|c|c|c|c|c|c|c|c|c|c|}
\hline Variables & $M$ & $S D$ & 1 & 2 & 3 & 4 & 5 & 6 & 7 & 8 & 9 \\
\hline 1. Age & 12.08 & 2.06 & 1 & & & & & & & & \\
\hline 2. Gender & - & - & $.25 *$ & 1 & & & & & & & \\
\hline 3. Job Status & - & - & $.24 *$ & $.54^{*}$ & 1 & & & & & & \\
\hline 4. Job Tenure & 14.21 & 8.04 & .09 & $.20 *$ & .07 & 1 & & & & & \\
\hline 5. Emotional Int. & 34.28 & 5.06 & $.21^{*}$ & $.32 *$ & .06 & $.01 *$ & 1 & & & & \\
\hline 6. P. Affectivity & 7.01 & 3.20 & .01 & $.33^{*}$ & .07 & .00 & $.39 *$ & 1 & & & \\
\hline 7. N. Affectivity & 6.23 & 2.01 & .09 & $.21^{*}$ & .03 & .08 & $-.21 *$ & $-.32 *$ & 1 & & \\
\hline 8. Deep Acting & 09.70 & 4.40 & $.16^{*}$ & .02 & .01 & .09 & $.26^{*}$ & $.23^{*}$ & $-.41 *$ & 1 & \\
\hline 9. Surface Acting & 13.04 & 19.72 & .04 & .12 & .05 & .05 & $-.16^{*}$ & $-.29 *$ & $.13^{*}$ & $.17 *$ & 1 \\
\hline
\end{tabular}

Note: $* * p<.01 . * p<.05 ; \mathrm{M}=$ Mean; $\mathrm{SD}=$ Standard Deviation; Emotional L. $=$ Emotional Labour; P. Affectivity $=$ Positive Affectivity; N. Affectivity $=$ Negative Affectivity.

Results in Table 1 showed that emotional intelligence was positively related to deep acting $(\mathrm{r}(275)=.26, p<.05)$. This suggests that bank employees with higher emotional intelligence are more likely to deep act to meet positive display rule. However, the results showed emotional intelligence was negatively related to surface acting (r (275) 
$=-.16, p<.05)$.

Positive affectivity had a significant positive relationship with deep acting $(\mathrm{r}(275)=.23, p<.05)$, suggesting that bank workers high in positive affectivity tend to engage in deep acting. However, positive affectivity was negatively related to surface acting $(\mathrm{r}(275)=-.29, p<.05)$. Negative affectivity on the other hand, had a significant positive relationship with surface acting $(\mathrm{r}(275)=.13, p<.05)$ but was negatively related to deep acting $(\mathrm{r}(275)=-.41, p<.05)$.

To test the hypotheses of this study, a 3-step hierarchical multiple regression analyses was performed. The results are presented in Table 2.

Table 2. Hierarchical Multiple Regression on Emotional Intelligence, Affectivity, and Emotional Labour Strategies.

\begin{tabular}{|c|c|c|c|c|c|c|}
\hline \multicolumn{7}{|l|}{ Dependent Variables } \\
\hline & & SA & & & DA & \\
\hline Predictor Variables & Step $1(\beta)$ & Step $2(\beta)$ & Step $3(\boldsymbol{\beta})$ & Step $1(\beta)$ & Step $2(\beta)$ & Step $3(\beta)$ \\
\hline Age & $-.19 *$ & $.36^{*}$ & $.13 *$ & $.12 *$ & $.38 *$ & $.31 *$ \\
\hline Job tenure & -.10 & -.15 & .05 & .06 & .02 & -.10 \\
\hline Emotional intelligence & & $-.42 * *$ & $.13 *$ & & $.16^{*}$ & $.11 *$ \\
\hline Positive affectivity & & & $-.35^{*}$ & & & $.33 *$ \\
\hline Negative affectivity & & & $.23 *$ & & & $-.21 *$ \\
\hline $\mathrm{R}^{2}$ & 0.03 & 0.20 & 0.27 & 0.01 & 0.12 & 0.18 \\
\hline$\Delta \mathrm{R}$ & 0.03 & 0.17 & 0.07 & 0.01 & 0.11 & 0.06 \\
\hline F-ratio & 2.31 & $10.21 *$ & $16.99^{*}$ & 0.8 & $7.45^{*}$ & $19.01 *$ \\
\hline$\Delta \mathrm{F}$ & 2.31 & $23.07 *$ & $8.49 *$ & 0.8 & $4.23 *$ & $6.25^{*}$ \\
\hline
\end{tabular}

Note: $* p<.01 . * * p<.01 \mathrm{~N}=277 . \mathrm{SA}=$ Surface Acting; $\mathrm{DA}=$ Deep Acting; $\mathrm{EL}=$ Emotional Labour.

Demographic variables were entered in step 1 . The results in Table 2 indicated that age had significant negative influence on surface acting $(\beta=-.19 ; p<.05)$ but positively related to deep acting $(\beta=.12 ; p<.05)$. This implies that as employee grow older, the more they engage in deep acting than surface acting. This may be possible because there are some evidences from research that older people with more life experience have higher levels of emotional intelligence. Positive emotional experiences also become more salient to people as they grow older because they realize that their lifespan is finite (Dahling \& Perez, 2010).

In step 2, emotional intelligence was entered along with the demographic variables. The results showed that emotional intelligence positively related to deep acting ( $\beta$ $=.16 ; p<.05)$ but negatively related to surface acting $(\beta=-$ $.42 ; p<.05)$. This means that bank employees with high emotional intelligence were more inclined to engage in deep acting. These results supported hypothesis 1 .

Positive and negative affectivity were introduced in step 3 . As shown in the results in Table 2, positive affectivity had a significant positive influence on deep acting $(\beta=.33 ; p<.05)$ but was negatively related to surface acting $(\beta=-.35 ; p<.05)$. This implies that bank employees with positive affectivity were more inclined to deep act than surface act to meet positive display rules. However, while negative affectivity was positively related to surface acting $(\beta=.23 ; p<.05)$, it negatively influence deep acting $(\beta=-.21 ; p<.05)$. These suggest that bank workers with negative affectivity tend to surface act than deep act to meet positive display rules. Positive and negative affectivity alone accounted for just $7 \%$ and $2 \%$ change in surface acting and deep acting respectively. With these results, hypotheses 2 and 3 were supported.

\section{Discussion}

The purpose of this study was to examine how emotional intelligence, positive affectivity, and negative affectivity were related to the use of emotional labour strategies among bank employees in Nigeria. As hypothesized, bank employees who had high emotional intelligence tend to utilize deep acting. This result is in consistent with Côté (2005) findings which revealed that individuals high in emotional intelligence reported employing deep acting than surface acting when performing emotional labor. The finding is also confirmed by the findings of Ehigie et al. (2012). They found that frontline hotel workers with high level of emotional intelligence exhibited deep acting during interpersonal interactions. The finding is also in tandem with the findings of Brotheridge (2006) and Dore et al. (2006); they reported that tendency to deep act increased with high level of emotional intelligence.

Possible explanations could be that emotionally intelligent bank employees have the ability to perceive, understand, and manage their emotional feelings and customers emotions. These employees are capable of creating positive emotions in themselves and are better equipped to change their own internal emotions in attempts to conform to emotional display rules compared with bank employees with low levels of emotional intelligence. Bank employees with low emotional intelligence lack the necessary skills to create positive emotions in themselves and employ more adaptive emotion regulation strategies such as deep acting. Thus, these employees may choose to surface act, which is a relatively simple, response-focused approach to managing emotions. This corroborates the assertion of Grandey (2000) who submitted that individuals who do not know how to regulate their emotions tend to engage more in surface acting and less in deep acting.

The results of this study also revealed that positive affectivity positively related to deep acting but negatively related to surface acting. This implies that bank workers high in positive affectivity were more inclined to use deep acting rather than surface acting to meet positive display rules. This is consistent with the findings of Johnson (2004) which revealed a significant positive relationship 
between positive affectivity and deep acting. The present findings also corroborated Gosserand et al. (2005) findings. The authors reported that employees with high positive affectivity always choose to engage in deep acting instead of surface act.

The preference for deep acting over surface acting is likely because these individuals are generally predisposed to experience positive emotions. So, on the occasions when they experience negative emotions that conflict with display rules, they are more likely to try to change their feelings via deep acting than to provide fake expressions via surface acting. Moreover, because bank display rules mandate the expression of positive emotion and suppression of negative emotion, they are likely to be favorable to bank employees high in positive affectivity because this approximates their natural state of being (i.e. positive mood states).

Negative affectivity on the other hand, positively correlated with surface acting but had a negative relationship with deep acting. It means that bank employees with high negative affect tend to utilize surface acting than deep acting to meet positive display rules, because such a strategy only modifies the expression of emotion, not the felt emotion (i.e. the negative mood). These are in consonance with previous findings of Brotheridge, et al., (2002), Brotheridge, et al., (2003), and Gosserand, et al., (2005). These authors reported that surface acting increases with negative affectivity. This was also corroborated by the findings of Cheung, et al. (2009) who reported that Chinese employees with negative affectivity tended to engage in surface acting. However, the findings contradict Ehigie, et al. (2012) findings which revealed no significant relationship between neuroticism or negative affectivity and surface acting.

It might be suggested that bank employees high in negative affectivity are more likely to surface act in order to obey positive display rules, because these rules call for expressions that conflict with their general negative mood states. Since these individuals are always in negative or bad moods, surface acting which only modifies the expression and not the feelings would be chosen more frequently than deep acting which modifies the feelings. This is because those high in negative affectivity often finds it difficult to suppress their deeply felt negative emotions (Schaubroek \& Jones, 2000). So, the only way they can conform to the positive display rules of the bank is by modifying or faking their emotional display or expressions.

\section{Conclusion and Implications of the Study}

This present study has made valuable contribution to emotional labour literature by showing that emotional intelligence significantly predict the use of emotional labour strategies among bank employees' in Nigeria. This result suggests important practical implication for bank management and human resource managers especially in the area of employees' development. This finding informs the need for bank management to train their employees on emotional intelligence and include training on emotional intelligence into their training manuals and policy. Moreover, human resource managers should train bank employees with low emotional intelligence on how to perform deep acting because deep acting has been associated with positive outcomes such as personal authenticity, personal accomplishment, and lower likelihood of revealing negative emotions, and job satisfaction and performance (Johnson et al. 2007).

The findings of this study also indicated that bank employees with positive affectivity tend to utilize deep acting to meet positive display rules whereas those with negative affect tend to utilize surface acting. Since banks in Nigeria require that their employees display positive emotions and suppress negative emotions, we recommend that during recruitment and selection exercises, employees with positive affectivity should be targeted. Moreover, there is a need for human resource managers of various banks to train bank employees with negative affectivity on how to perform deep acting.

This study was not without some short-comings. The first short-coming of this study was the sample size used. Apart from the fact that the sample size was too small, the results of the current study may not represent bank workers in Nigeria because the sample was drawn from the capital city of just a southwest state in Nigeria. Replication of this study among larger sample of bank workers across the country may ensure the generalizability of the current findings. Secondly, the cross-sectional nature of the data calls into question any inferences that could be made concerning the directionality of relationships. Another limitation of the study is the use of same-source data, which increases concern for common method bias.

\section{References}

[1] Amazue, L. O., Onyishi, I. E., \& Amazue, L. E. (2014). Surface acting and distress tolerance as predictors of workplace deviance among Nigeria commercial banks workers. African Journal of Business Management, 8(15), $582-587$.

[2] Ashforth, B. E. \& Humphrey, R. H. (1993). Emotional labor in service roles: the influence of identity. Academy of Management Review, 18, 88-115.

[3] Balogun, A. G. (2014). Dimensions of job stress as correlates of withdrawal intention among employees in merged and acquired banks in Nigeria. Nigerian Psychological Research. 2, 225-236.

[4] Bolton, S. C. (2005). Emotion management in the workplace. London: Palgrave MacMillan.

[5] Bono, J. E., \& Vey, M. A. (2005). Toward understanding emotional management at work: A quantitative review of emotional labor research. In C. E. J. Hartel, W. J. Zerbe, \& N. M. Ashkanasy (Eds.), Emotions in organizational behavior (pp. 213-233). Mahwah, NJ: LEA Publishers. 
[6] Brotheridge, C. M. (2006). The role of emotional intelligence and other individual difference variables in predicting emotional labor relative to situational demands. Psicothema, $18,139-144$

[7] Brotheridge, C. M., \& Lee, R. T. (2003). Development and validation of the emotional labour scale. Journal of Occupational and Organizational Psychology, 76, 365-379.

[8] Brotheridge, C. M., \& Grandey, A. A. (2002). Emotional labor and burnout: Comparing two perspectives of 'people work'. Journal of Vocational Behavior, 60, 17-39.

[9] Chau, S. L., Dahling, J. J., Levy, P. E., \& Diefendorff, J. M. (2009). A predictive study of emotional labor and turnover. Journal of Organizational Behavior, 30: 1151-1163.

[10] Cheung, F. Y., \& Tang, C. S., (2009). The influence of emotional intelligence and affectivity on emotional labour strategies at work. Journal of Individual Differences, 30(2), 75-86.

[11] Chu K. H. L., (2002). The effects of emotional labor on employee work outcomes. Unpublished Dissertation, Virginia Polytechnic Institute and State University.

[12] Côté, S. (2005). A social interaction model of the effects of emotion regulation on work strain. Academy of Management Review, 30, 509-530.

[13] Dahling, J.J., \& Perez, L.A. (2010). Older worker, different actor? Linking age and emotional labor strategies. Personality and Individual Differences, 48, 574-578.

[14] Diefendorff, J. M., \& Richard, E. M. (2003). Antecedents and consequences of emotional display rule perceptions. Journal of Applied Psychology, 88, 284-294.

[15] Diefendorff, J. M., Croyle, M. H., \& Gosserand, R. H. (2005). The dimensionality and antecedents of emotional labor strategies. Journal of Vocational Behavior, 66, 339-359.

[16] Dore T and Austin E (2006). Do Emotional Intelligence and Personality Predict the Way That Emotional Labour is Performed? A thesis submitted to the University of Edinburgh.

[17] Ehigie, B. O., Oguntuase, R. O., \& Ibode, F. O., \& Ehigie, R. I. (2012). Personality factors and emotional intelligence as predictors of Frontline Hotel employees' emotional labor. Global Advanced Research Journal of Management and Business Studies, 1(9), 327-338.

[18] Goleman D (1998). Working with the Emotional Intelligence. New York: Bantam Books.

[19] Goleman, D. (1995). Emotional Intelligence: Why It Can Matter More Than IQ, Bantam Books.

[20] Gosserand, R. H., \& Diefendorff, J. M. (2005). Emotional display rules and emotional labor: The moderating role of commitment. Journal of Applied Psychology, 90, 1256-1264.

[21] Gosserand, R.H., \& Diefendorff, J. M. (2005). Emotional display rules and emotional labour: The moderating role of commitment. Journal of Applied Psychology, 90(6), 12561264.

[22] Grandey, A. A. (2000). Emotional regulation in the workplace: A new way to conceptualize emotional labor. Journal of Occupational Health Psychology, 5, 95-110.
[23] Grandey, A. A., (2003). When the show must go on: Surface acting and deep acting as determinants of emotional exhaustion and peer-rated service delivery. Academy of Management Journal, 46, 86-96.

[24] Henderson, A. (2001). Emotional labor and nursing: an underappreciated aspect of caring work. Nursing inquiry, 8(2), 130138.

[25] Hesmondhalgh, David; Baker, Sarah (2008). Creative Work and Emotional Labour in the Television Industry. Theory, Culture \& Society 25(7\&8), 97-118.

[26] Hochschild, A. R. (1983). The managed heart: The commercialization of feeling. Berkeley: University of California Press.

[27] Johnson, H. M. (2004). The story behind service with a smile: The effects of emotional labor on job satisfaction, emotional exhaustion, and affective well-being. Unpublished master's thesis, University of South Florida, Tampa, Florida.

[28] Johnson, H. M., \& Spector, P.E. (2007). Service with a smile: Do emotional intelligence, gender, and autonomy moderate the emotional labor process? Journal of Occupational Health Psychology, 12, 319-333.

[29] Karatepe, O. M., \& Aleshinloye, K. D. (2009). Emotional dissonance and emotional exhaustion among hotel employees in Nigeria. International Journal of Hospitality Management, $28,349-358$.

[30] Larson, E. B. Yao, X. (2005). Clinical Empathy as Emotional Labor in the Patient-Physician Relationship, JAMA, 293(9), 1100-1106.

[31] Morris, J. A., \& Feldman, D. C. (1996). The dimensions, antecedents, and consequences of emotional labor. Academy of Management Review, 21, 986-1010.

[32] Noor N. M., \& Zainuddin, M. (2011). Emotional labor and burnout among female teachers: Work-family conflict as mediator. Asian Journal of Social Psychology, 1-11

[33] Ogungbamila, B., Balogun, A. G., Ogungbamila, A., \& Oladele, R. S. (2014). Job stress, emotional labor, emotional intelligence as predictors of turnover intention: evidence from two service occupations. Mediterranean Journal of Social Sciences, 5(6), 319-325.

[34] Salovey, P., \& Mayer, J. D. (1990). Emotional intelligence. Imagination. Cognition and Personality, 9(3), 185-211.

[35] Schaubroeck, J. \& Jones, J. R. (2000). Antecedents of workplace emotional labor dimensions and moderators of their effects on physical symptoms. Journal of Organizational Behavior, 21, 163-183.

[36] Weiss, H., \& Cropanzano, R. (1996). Affective events theory: A theoretical discussion of the structure, causes, and consequences of affective experiences at work. Research in Organizational Behavior, 18, 1-74.

[37] Watson, D., Clark, L. A., \& Tellegen, A. (1988). Development and validation of brief measures of positive and negative affect: The PANAS scales. Journal of Personality and Social Psychology, 54, 1064-1070.

[38] Wharton, A. S., \& Erickson, R. J. (1993). Managing emotions on the job and at home: Understanding the consequences of multiple emotional rules. Academy of Management Review, 18, 457-486. 
44 Anthony G. Balogun et al: : Service with a Smile: Roles of Emotional Intelligence and Affectivity on the Use of Emotional Labour Strategies Among Bank Employees

[39] Wong, C., \& Law, K. (2002). The effects of leader and follower emotional intelligence on performance and attitude: An exploratory study. The Leadership Quarterly, 13, 243-274.
[40] Zeithaml, V., Bitner, M., \& Gremler, D. (2006).Service marketing: integrating customer focus across the firm. New York: John Wiley \& Sons. Inc. 